\title{
Erratum to: Identification of molecular variants of the nonrestoring restorer-of-fertility 1 allele in sugar beet (Beta vulgaris L.)
}

Takashi Ohgami $^{1} \cdot$ Daisuke Uchiyama $^{1} \cdot$ Sachiyo Ue $^{1} \cdot$ Rika Yui-Kurino $^{1} \cdot$

Yu Yoshida $^{1} \cdot$ Yoko Kamei $^{1} \cdot$ Yosuke Kuroda $^{2} \cdot$ Kazunori Taguchi $^{2} \cdot$ Tomohiko Kubo $^{1}$

Published online: 22 April 2017

(C) Springer-Verlag Berlin Heidelberg 2017

Erratum to: Theor Appl Genet (2016) 129:675-688

DOI 10.1007/s00122-015-2656-0

In the last sentence of "Materials and methods" section, one of the accession numbers should have been LC085628, not LC685268.

The online version of the original article can be found under doi:10.1007/s00122-015-2656-0.

Tomohiko Kubo

tomohiko@abs.agr.hokudai.ac.jp

1 Research Faculty of Agriculture, Hokkaido University, N-9, W-9, Kita-Ku, Sapporo 060-8589, Japan

2 Hokkaido Agricultural Research Center, National Agriculture and Food Research Organization, Memuro 082-0081, Japan 